\title{
Utilização de macrófitas aquáticas na produção de adobe: um estudo de caso no reservatório de Salto Grande (Americana - SP)
}

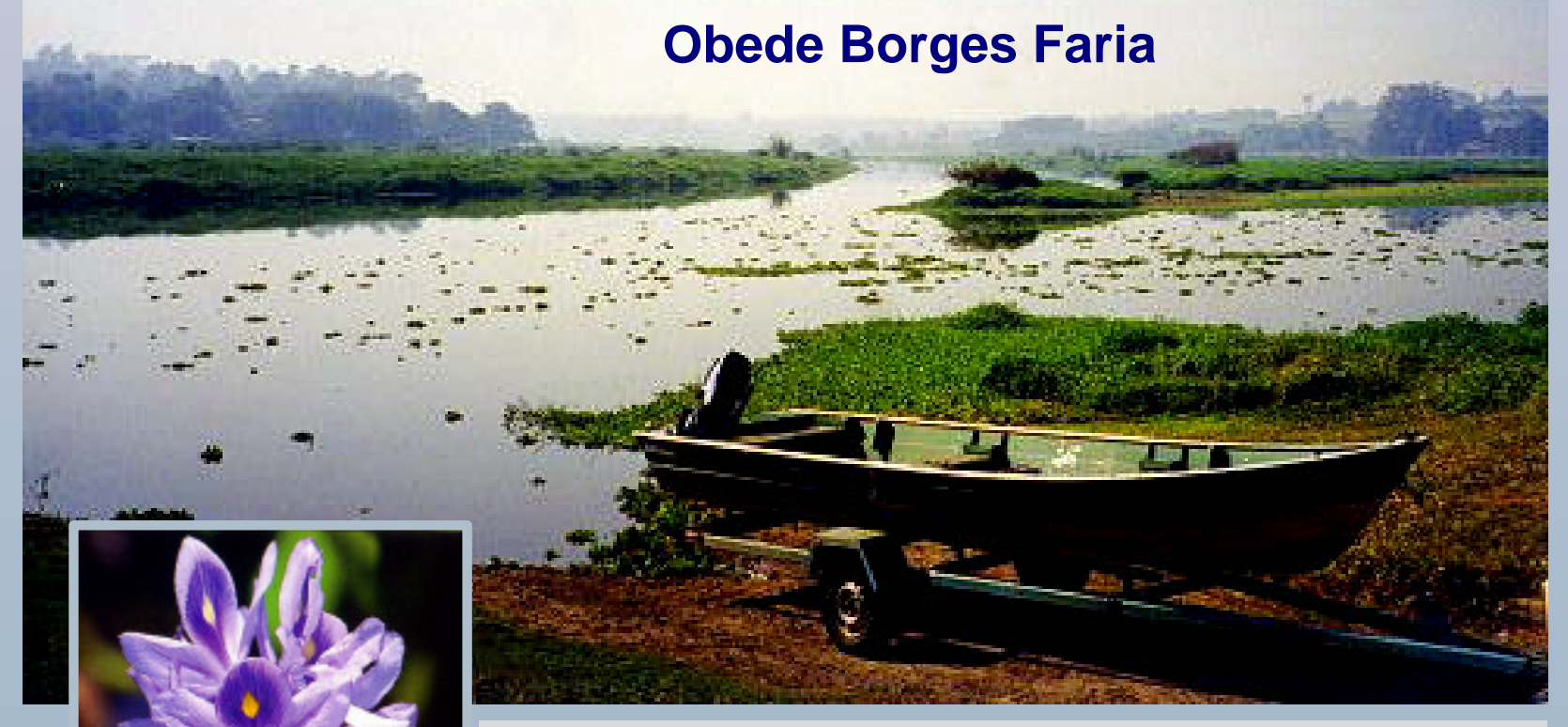

Tese apresentada à Escola de Engenharia de São Carlos, da Universidade de São Paulo, como parte dos requisitos para obtenção do título de Doutor em Ciências da Engenharia Ambiental.

Orientador: Prof. Assoc. Evaldo Luiz Gaeta Espíndola

\section{São Carlos} 2002 
Faria, Obede Borges

Utilização de macrófitas aquáticas na produção de adobe : um estudo de caso no reservatório de Salto Grande (Americana - SP) / Obede Borges Faria. -- São Carlos, 2002 .

Tese (Doutorado) -- Escola de Engenharia de São Carlos-Universidade de São Paulo, 2002.

Área: Ciências da Engenharia Ambiental.

Orientador: Prof. Assoc. Evaldo Luiz Gaeta Espíndola.

1. Materiais de construção. 2. Construção em terra. 3. Adobe. 4. Macrófitas aquáticas. 5. Nutrientes. 6. Eutrofização de lagos. 7. Manejo integrado de reservatório. 


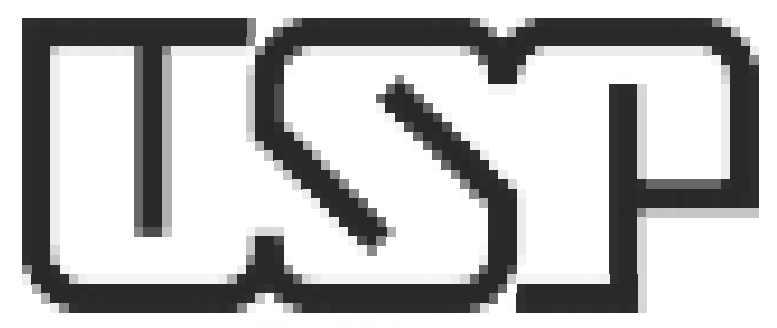

\section{Universidade de São Paulo}

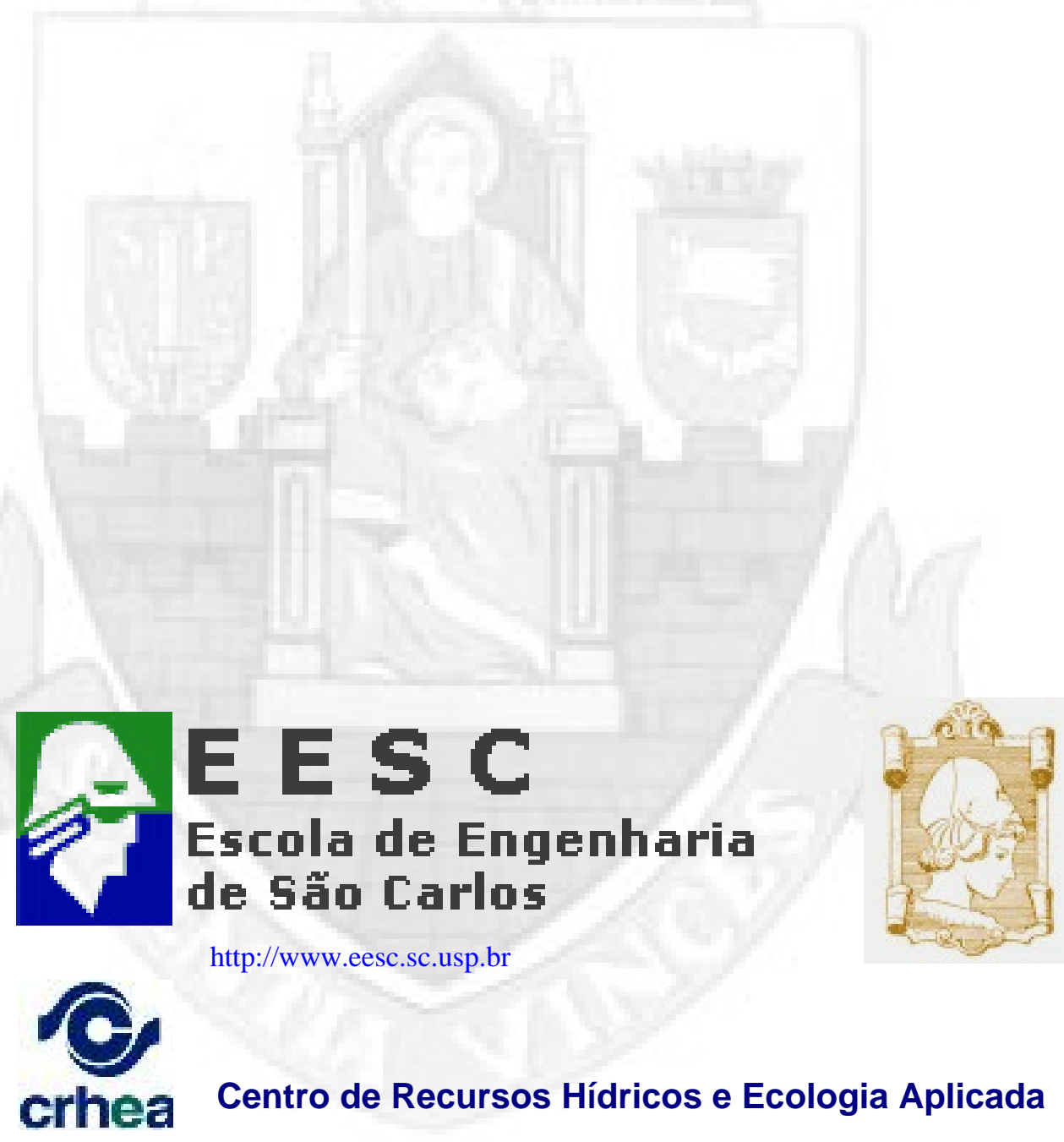

DEPARTAMENTO DE HIDRÁULICA E SANEAMENTO - EESC - USP Av. do Trabalhador Sancarlense, 400 - Centro - Caixa Postal 359 - CEP 13560-250 - São Carlos-SP Tels: (16) 273-9534 / 273-9552 Fax: (16) 273-9550

PABX Campus: (16) 273-9333 


\section{FOLHA DE JULGAMENTO}

Candidato: Engenheiro OBEDE BORGES FARIA

Tese defendida e julgada em 28-10-2002 perante a Comissão Julgadora:

Prof. Assoc. EVALDO LUIZ GAETA) ESPÍNDOLA (Orientador)

APROUAR

(Escola de Engenharialde São Carlos/USP)

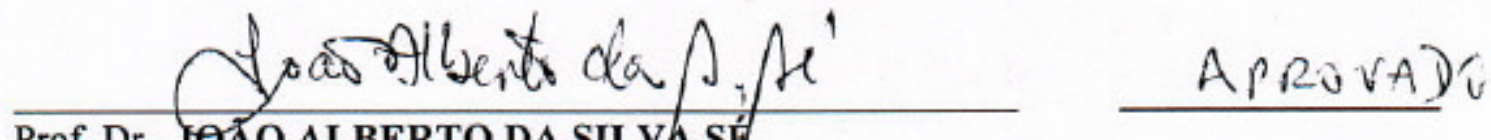

Prof. Dr. JUĂO ALBERTO DA SILVA SÉ

(Centro Universitário de Araraquara/UNIAR'A)

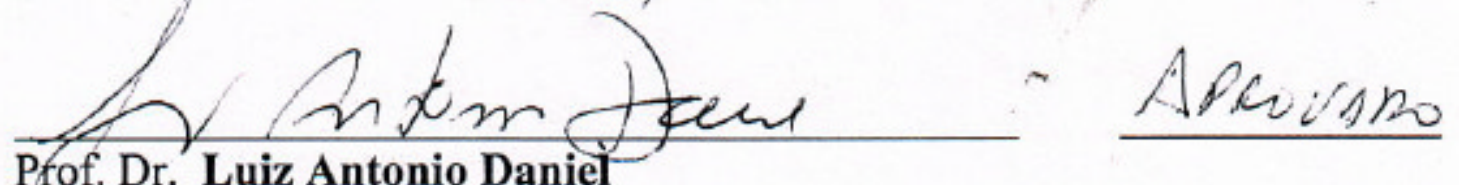

(Escola de Engenharia de São Carlos/USP)

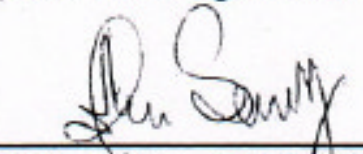

Prof. Assoc. HOLMER SAVASTANO JÚNIOR

Aptois

(Faculdade de Zooteenia e Engenharia de Alimentos/USP)

Prof. Dr. JAIRO SALIM PINHEIRO DE LIMA

Ajocisanis

(UNESP/Campus de tha Solteira)

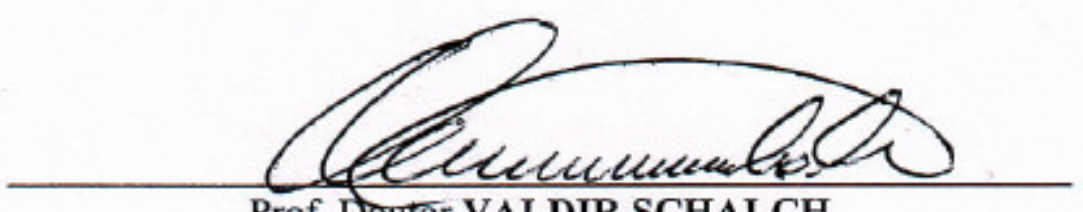

Prof. Doutor VALDIR SCHALCH

Coordenador do Programa de Pós-Graduação

em Ciências da Engenharia Ambiental

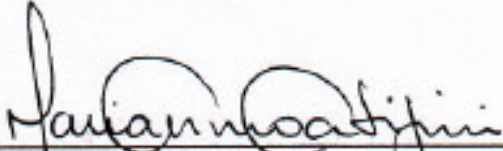

Profa. Assoc. MARIA DO CARMO CALIJURI

Presidente da Comissão de Pós-Graduação 


\section{USP Fênix - Sistema de Pós Graduaçăo}

Escola de Engenharia de Săo Carlos

\section{Certificado de Defesa}

Certifico, para os devidos fins, que o(a) $\mathrm{Sr}$ (a). Obede Borges Faria, código USP 1552418 , defendeu em sessão pública no dia 28 de outubro de 2002, a Tese de Doutorado na área de Ciências da Engenharia Ambiental intitulada "Utilização de macrófitas aquáticas na produçăo de adobe: um estudo de caso no reservatório de Salto Grande (Americana - SP)", tendo sido aprovado(a), fazendo jus ao título de Doutor em Ciências da Engenharia Ambiental, homologado pela Comissăo de Pós-Graduaçăo em 29 de novembro de 2002.

Săo Carlos, 29 novembro de 2002.

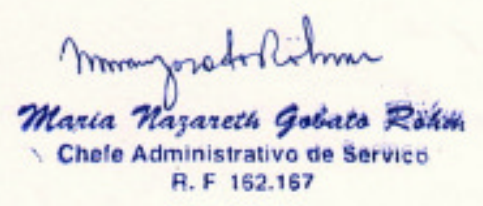

